\title{
EVOLUTION OF HIGH-LATITUDE BIOTAS
}

CRAME, J. Alistair, British Antarctic Survey, Natural Environment Research Council, High Cross, Madingley Road, Cambridge CB3 0ET, U.K.

With the recent rapid improvement in the quality of the fossil record in both polar regions it has become possible to examine critically the development of high-latitude faunas and floras through time. Within arctic regions, distinctive biotas have been present, at least intermittently, since the early Permian, and in antarctic regions they can be traced back to the early Middle Devonian. It would appear that, whenever continents (and continental shelves) moved into the high latitudes they were the sites of significant biotic differentiation.

To investigate the ways in which taxa may have accumulated in the high latitudes through time, three simple global models have been proposed. In the first of these it is envisaged that major groups of plants and animals arose in the low latitudes and disseminated subsequently into the polar regions. Here they would become relicts and the latter would be regarded as refugia. The second model is almost exactly the reverse of the first in that it proposes that certain taxa arose in the polar regions and then spread, through time, into the low latitudes. Such a process may at first sight seem less likely, but the Antarctic fossil record in particular is providing important evidence to suggest that certain major groups of both plants and animals had a highlatitude origin. The third model differs substantially from the previous two in that it makes no a priori assumptions about either centres of origin or the process of dispersal. It merely states that, at certain times in the past, widespread distribution patterns have been disrupted in the low latitudes to form disjunct populations in the northern and southern hemispheres. It results in the classic bipolar pattern, which can now be traced back to at least the Early Jurassic period.

A major phase of Jurassic - Cretaceous bipolarity can be attributed to tectonic vicariance as the Pangean supercontinent disintegrated, and a major late Paleogene - early Neogene one can be related to climatic vicariance. Such hypotheses are attractive as they are testable by cladistic analysis. Although data available so far are limited, both fossil and living benthic molluscs offer considerable scope for future work. 